\title{
An Operational Technique of Forecasting Thunderstorms Along the Lee Slopes of a Mountain Range
}

\author{
JoHn F. Henz \\ Dept. of Atmospheric Science, Colorado State University, Forl Collins 80521
}

(Manuscript received 19 May 1972, in revised form 3 August 1972)

ABSTRACT

\begin{abstract}
The lee slopes of the Rocky Mountains from Montana to New Mexico have long been recognized as prime breeding grounds for lee slope thunderstorms. A simple forecast technique is introduced which models the formation of these thunderstorms. It provides the operational meteorologist with an accurate short range forecast tool. Three forecast parameters are used to model thunderstorm development. The Mountain Layer Stability (MLS) measures the stability of the mountain thermal bubbles as they are lifted in the valley breeze circulation. The Max Heating Index (MHI) measures the thermal energy on the plains to trigger lee slopes cumulus into thunderstorms at the time of maximum heating. The Filter Index is used to separate borderline occurrences into a distinct forecast.
\end{abstract}

\section{Introduction}

During the months of May through August the primary forecast problem along the Front Range of the Rocky Mountains is the occurrence of lee slope thunderstorms. Most lee slope thunderstorms occur between the hours of 1200 and 2200 (all times MDT) with exceptions being directly related to the passage of a front or strong upper air thermal trough. Convective activity is initiated by the release of unstable "thermal bubbles" from the heated mountain slopes. Under favorable conditions these "thermal bubbles" grow into towering cumuli ( $\mathrm{TCu}$ ) and move over the Great Plains steered by the ambient flow where their growth is further accelerated into thunderstorms.

This study was initiated in 1968 to develop an accurate objective thunderstorm/no thunderstorm forecast technique for Buckley Air National Guard Base, Aurora, Colo. (referred to as BKF). The operational requirements placed on the study required it to model the thermodynamic development cycle of lee slope thunderstorms with data normally available to the operational meteorologist. The forecast was required to be valid within a 12 -mi radius around the $B K F$ representative observation site (referred to as ROS) and provide at least a 1-hr leadtime during the hours of 1200-2200.

\section{Related climatology and topography}

The development of lee slope thunderstorms is directly related to the topographical effect of the Rocky Mountains and the Great Plains on the normal convective process. The local topography surrounding BKF is presented in Fig. 1. The most outstanding feature is the
Front Range of the Rocky Mountains which rises to the southwest through the northwest. Directly southeast through southwest of BKF, the Palmer Lake Divide, a connecting spur of the Rockies, juts out into the Great Plains. Its vertical extent varies from $8500 \mathrm{ft} \mathrm{MSL}$, where it joins the Rockies, to $4500 \mathrm{ft}$ MSL at the

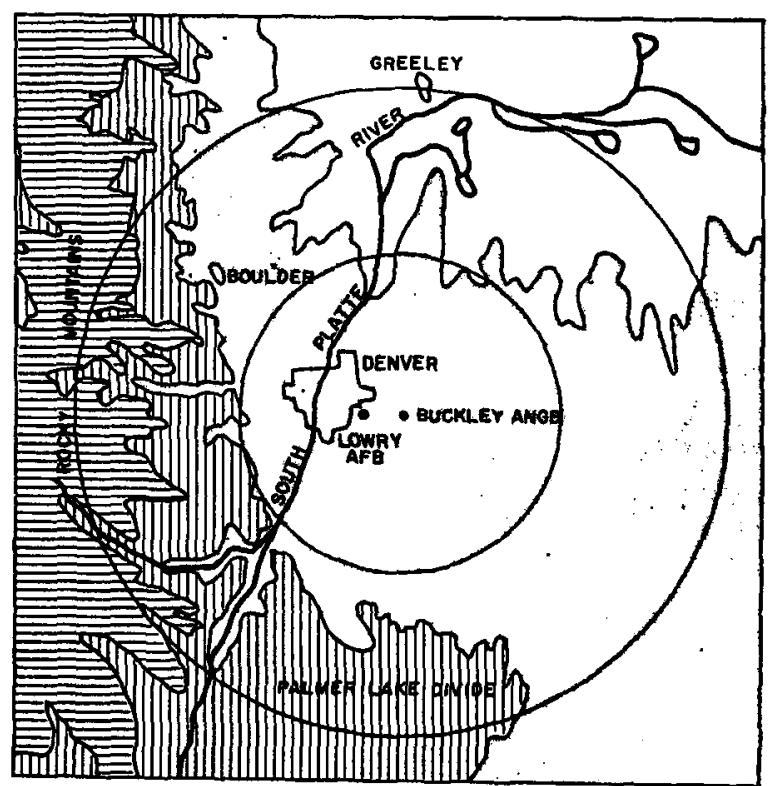

LEGEND
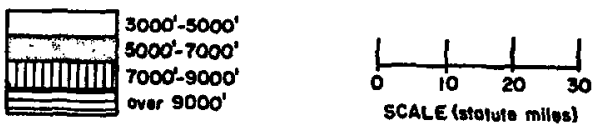

FIG. 1. Terrain map of area surrounding Buckley ANGB. 


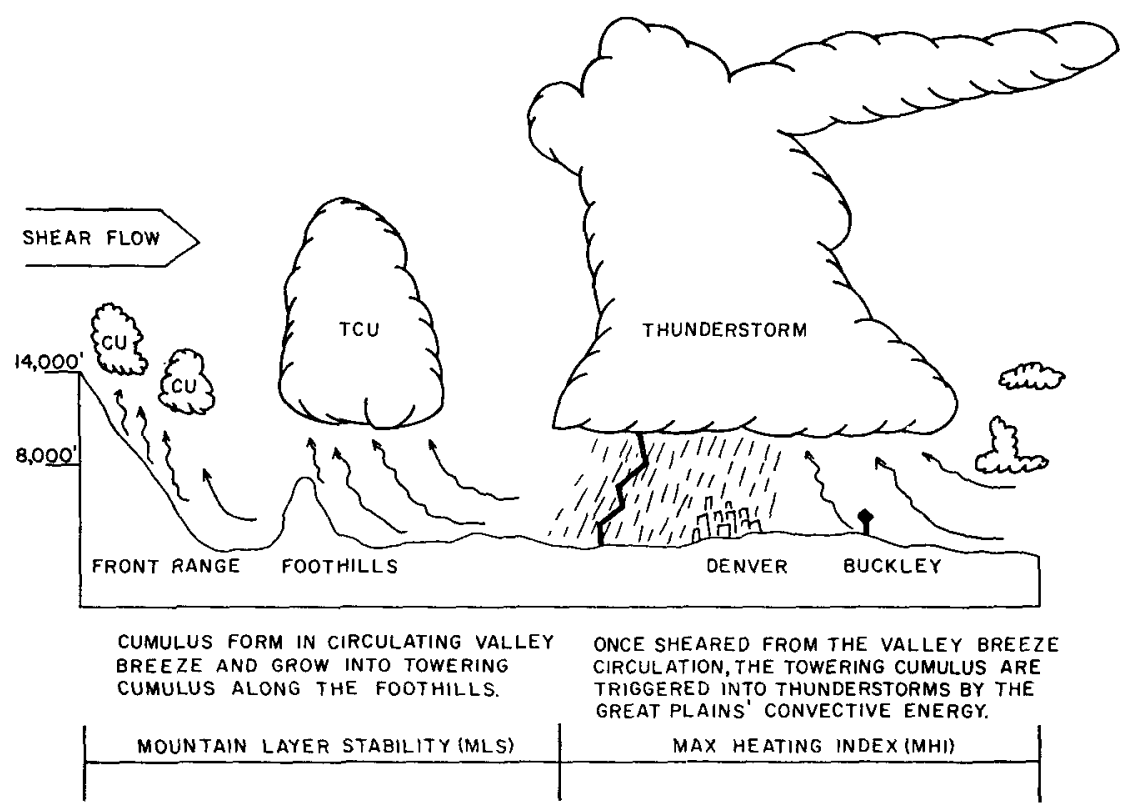

Fig. 2. Growth pattern of lee slope thunderstorms.

Colorado-Kansas border. These areas, including the foothills of the Rockies, are preferred breeding grounds for lee slope thunderstorms.

Table 1 contains the average number of thunderstorm days for each month, May through August, from 1961-70, and Table 2, the hourly distribution of thunderstorms by months for the period 1966-70. It can easily be seen from Table 2 that thunderstorms occur mainly during the afternoon through midevening hours. This suggests a strong correlation between thunderstorm development and the solar heating cycle. Those thunderstorms observed between 2200 and 1200 are almost always related to the passage of a strong 500 - or 700 -mb thermal trough.

\section{Lee slope thunderstorm development cycle}

In an effort to model accurately the thermodynamic processes which cause lee slope thunderstorms, numerous trips were made to the foothills region of the Rockies to observe lee slope convection. A consistent development pattern soon became evident and it served as the basis of this study.

It has been well documented in studies by Braham and Draginis (1960), Battan and Kosiodius (1960), and Dirks (1968), that mountain slopes, especially those facing the sun, strongly absorb incident radiation. Air

TAPLE 1. Average thunderstorm occurrence days per month, $1961-70$.

\begin{tabular}{ccccc} 
& May & Jun & Jul & Aug \\
\hline Average & 7.8 & 11.4 & 13.7 & 10.0
\end{tabular}

immediately adjacent to the surface is heated by conduction from below, and a valley breeze circulation is the eventual result. A detailed discussion of a numerically simulated valley breeze circulation can be found in Dirks (1969). Evidence of this valley breeze extending out into the Great Plains can be found in the diurnal wind shift often observed at BKF between 1000 and 1200. Prior to 1000 the wind is southerly, draining off the mountains. After 1200 the wind is northeast, blowing toward the heated mountains. The wind shift is common from late spring until late fall when diurnal heating is most pronounced and when large-scale synoptic systems are least likely to mask it. The initiation of cumulus cloud over mountainous terrain in a numerical study is described in Orville (1965). A further study of mountainous convection by Orville (1968) points out the importance of ambient wind effects on the initiation of mountain cumulus cloud.

Once the valley breeze circulation is established, "bubbles" of heated air rise from the slopes. As the lifted condensation level (LCL) of these bubbles is reached, they become visible as cumulus clouds. Often the ambient wind shears the thermal bubble from the slope circulation and causes it to drift toward the Great

TABLE 2. Thunderstorm occurrences for time period 1966-70.

\begin{tabular}{crccc}
\hline & May & Jun & Jul & Aug \\
\hline $\begin{array}{c}\text { Time } \\
\text { (MD') }\end{array}$ & & & & \\
$1200-2200$ & 48 & 59 & 84 & 58 \\
$2300-1100$ & 2 & 9 & 10 & 3 \\
\hline
\end{tabular}




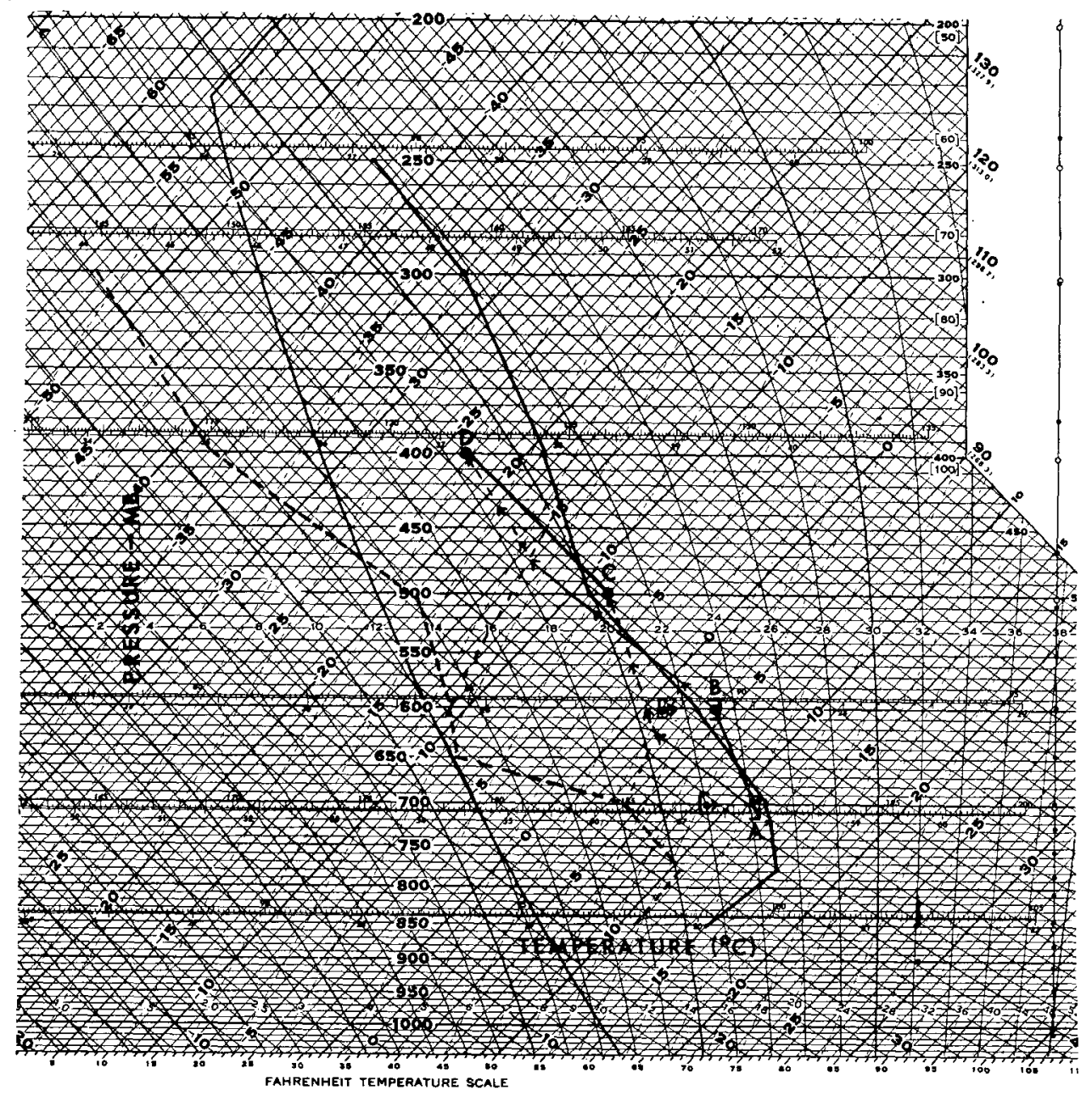

FIG. 3. Example of mountain layer stability.

Plains to the east. Continued existence of this bubble or cumulus cloud, now deprived of its original source of energy, depends upon available low-level moisture and the ability of the heated Plains to maintain convection. If abundant hydro-thermodynamic energy is available, i.e., if considerable amounts of water vapor and sensible heat are brought to the vicinity of the pre-existing cumulus cloud by thermals originating on the Plains, it will grow quite rapidly into a thunderstorm. If either heating from below or moisture is deficient, the cloud will dissipate or develop slowly, seldom surpassing the TCu stage until well east of BKF. Fig. 2 depicts this development cycle. The further development of these thunderstorms into organized squall lines producing severe weather follows the pattern observed well away from the mountains, in the Plains or the Mid-West, though topography often serves to orientate these lines.

\section{Modeling the thunderstorm development cycle}

Modeling of this development cycle is divided into three sections: the Mountain Layer Stability (MLS), which measures the ability of the mountain slope environment to support growth of thermal bubbles; the Max Heating Index (MHI), which measures the thermal energy available over the Plains; and a Filter Index, used when the MLS and MHI do not result in a definite yes/no forecast.

\section{a. Modeling the valley breeze circulation}

The Mountain Layer Stability (MLS) is based upon observations of lee slope cumuli and is determined graphically from the 0600 Denver National Weather Service radiosonde data on a Skew $T, \log P$ diagram. In order to simulate the development of thermal bubbles within the valley breeze circulation, a parcel is lifted adiabatically from $750 \mathrm{mb}(\sim 8000 \mathrm{ft}$ MSL) to $700 \mathrm{mb}(\sim 10,000 \mathrm{ft} \mathrm{MSL})$. A second parcel is lifted adiabatically from 700 to $600 \mathrm{mb}(\sim 13,000 \mathrm{ft}$ MSL). These levels correspond to the elevations of the heated slopes. The effect of the additional energy added to the parcels by the heated slopes is simulated by adding $3 \mathrm{C}$ to both the lifted $700-$ and $600-\mathrm{mb}$ 


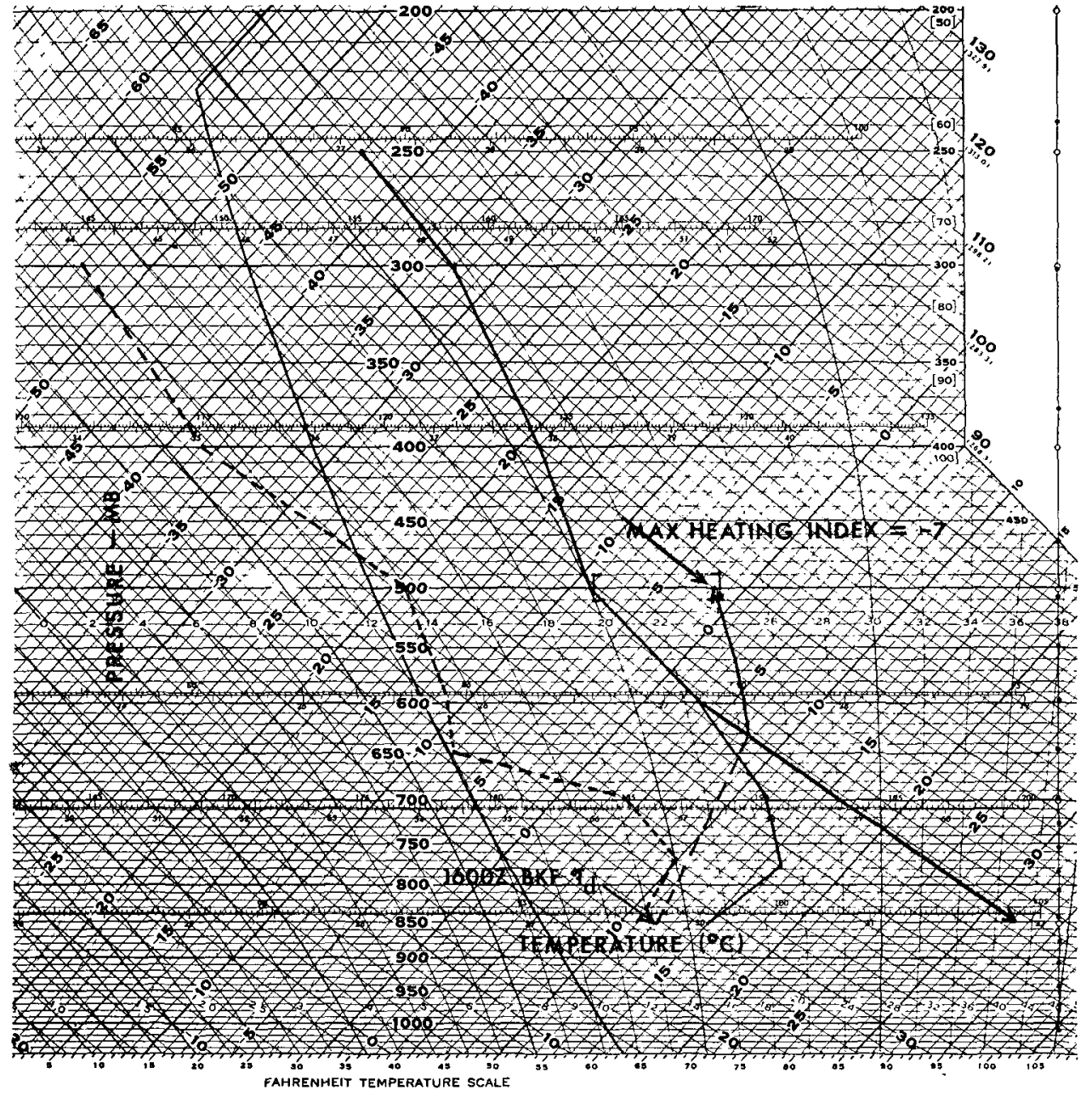

FIG. 4. Example of Max Heating Index computation.

parcel temperatures. See points $\mathrm{A}(700 \mathrm{mb})$ and $\mathrm{B}$ $(600 \mathrm{mb})$ in Fig. 3 . The straight line joining points $\mathbf{A}$ and $\mathbf{B}$ gives a representative vertical temperature profile through a thermal bubble.

Increasing the parcel temperatures by $3 \mathrm{C}$ is justified from a review of summertime thermographic traces at Berthoud Pass (11,500 ft MSL) approximately $55 \mathrm{n} \mathrm{mi}$ west-northwest of BKF provided by the National Forest Service, and at Niwot Ridge $(12,400 \mathrm{ft}$ MSL), approximately $45 \mathrm{n} \mathrm{mi}$ west-northwest of BKF, provided by the National Center of Atmospheric Research, and comparisons of free air and mountain slope temperature observations in the Rocky Mountain by Samson (1965). Each indicates that the slopes are at least 3C warmer, even under cloudy skies, than DEN RAOB soundings indicate for corresponding levels in the free air.

Normally the LCL over the mountains is above $600 \mathrm{mb}$. In order to simulate further lifting of the bubble to its LCL and into the ambient flow above the planetary boundary layer, the parcel represented by point $\mathrm{A}$ is lifted adiabatically to $500 \mathrm{mb}(\sim 18,000 \mathrm{ft} \mathrm{MSL})$ using the DEN RAOB 700-mb dew point. The thermodynamic condition of the parcel is now represented by point $\mathrm{C}$ in Fig. 3. Similarly, adiabatic ascent from point $\mathrm{B}$ to $400 \mathrm{mb}(\sim 24,000 \mathrm{ft} \mathrm{MSL})$ is accomplished using the $600-\mathrm{mb}$ dew point. The final condition of this second parcel is represented by point $\mathrm{D}$ in Fig. 3 .

The lapse rate within the growing thermal bubble, now perhaps a $\mathrm{TCu}$, is approximated by line $\mathrm{C}-\mathrm{D}$. The bubble lapse rate, $\Gamma_{\mathrm{C}-\mathrm{D}}$, is compared with the dry adiabatic $\Gamma_{d}$ and moist adiabatic $\Gamma_{m}$ lapse rates. In this paper lapse rates are considered negative except under inversion conditions. If $\Gamma_{m} \leqslant \Gamma_{\mathrm{C}-\mathrm{D}}$, the bubble is stable; the forecast is for no thunderstorm at BKF. If $\Gamma_{d} \leqslant \Gamma_{\mathbf{C}-\mathbf{D}}<\Gamma_{m}$ (conditional instability), the introduction of moisture at the base of the bubble, once it has moved out over the plains, can initiate further development. If $\Gamma_{\mathrm{C}-\mathrm{D}}<\Gamma_{d}$ (absolute instability), thunderstorm development is likely, and any moisture added to the bubble over the plains will merely accelerate its growth. 
Step 1. Use $1200 Z$ DEN RAOB for all calculations.

Step 2. If the mean wind - direction in the $10,000-20,000 \mathrm{ft}$ layer is $360-150$ degrees, circle NO TSTMS BUT CHECK FOR CB VCNTY.

Step 3. Mountain Layer Stability

a) Lift parcel at $750 \mathrm{MB}$ on $1200 \mathrm{Z}$ DEN RAOB to $700 \mathrm{MB}$ adiabatically (dry till saturated, then moist) and add $3^{\circ} \mathrm{C}$ to lifted $700 \mathrm{MB}$ temperature. Call this point A.

b) Lift parcel at $700 \mathrm{MB}$ to $600 \mathrm{MB}$ adlabatically as before and add $3^{\circ}$ to the lifted $600 \mathrm{MB}$ temperature. Call this point $\mathrm{B}$.

c) Join points $A$ and $B$ with a line. This is the mean lapse rate for the layer.

d) Lift parcel from point $\mathrm{A}$ to $500 \mathrm{MB}$ using the $700 \mathrm{MB}$ RAOB dew point for a molsture value. Call new point $C$.

e) Lift parcel from point $B$ to $400 \mathrm{MB}$ using $600 \mathrm{MB}$ RAOB dew point for a moisture value. Call new point $D$.

f) Join points $C$ and $D$ with a straight line. This is the mean lapse rate of the lifted layer.

g) Is line $C D$ absolutely stable, conditionally stable, or absolutely unstable. Circle one.

h) If line $C D$ is absolutely stable stop. FCST NO TSTMS!

i) If line $\mathrm{CD}$ is either conditionally stable or absolutely unstable continue to Step 4.

Step 4. Max heating index

a) Draw line from DEN RAOB's $600 \mathrm{MB}$ temperature to surface dry adiabatica11y.

b) Using this line and the $1600 \mathrm{Z}$ BKF surface dew point lift a parcel from the surface to $500 \mathrm{MB}$.

c) Subtract the temperature of the Iifted parcel from the $500 \mathrm{MB}$ temperature and write the reslt here ( ).

d) If this value 1s less than the monthly Max Heating Index values circle TSTMS: if more than, circle CB VCNTY. If the computed value is equal to the Monthly Max Heating Value compute the Filter Indices.

Fig. 5. Henz Lee Slope Thunderstorm Study Worksheet.

\section{b. Great Plains convection-MHI}

Whenever $\Gamma_{C-D}$ is conditionally or absolutely unstable, it is helpful to examine the amount of convective energy likely to be available over the plains at the time of maximum heating. This may be done through use of the Maximum Heating Index (MHI), which is derived by descending dry adiabatically from $600 \mathrm{mb}$ to the surface on the DEN RAOB. Using the resulting surface temperature (32C) and the $1000 \mathrm{MDT}$ BKF surface temperature dew point $(12 \mathrm{C})$, a parcel is lifted conventionally to $500 \mathrm{mb}$ where its temperature is subtracted from the $500-\mathrm{mb}$ DEN RAOB temperature. This temperature deviation is the MHI value. Fig. 4 illustrates the determination of an MHI value of -7 .

Unless a frontal inversion precludes normal diurnal heating, dry adiabatic descent from $600 \mathrm{mb}$ gives a conservative but reliable estimate of the maximum surface temperature and approximates the temperature stratification in the lowest $7000 \mathrm{ft}$ at the time of maximum heating. The 1000 surface dew point is available within the lead-time requirement for a thunderstorm forecast. The 1000 value is usually maintained or exceeded during the afternoon hours since winds with an easterly component are common then and higher moisture values are almost invariably found to the east.

Figs. 5 and 6 are the Henz Lee Slope Thunderstorm Study Worksheet, which summarizes the forecast technique used operationally at BKF. A definite correlation exists between MHI values and thunderstorm occurrences. Examination of 1966-70 data showed that when the MHI value in a given month is less than the critical value shown at the bottom of the worksheet, thunderstorms are probable. 
Step 5. Filter Index (Used only when specified by 3d)

a) Using $1200 Z$ DEN RAOB Temperature and dew point lift parcel from $700 \mathrm{MB}$ to $500 \mathrm{MB}$ and subtract lifted parcel's temperature from $500 \mathrm{MB}$ temperature. Record here_. This is the $700-$ 500 MB Filter Index Value.

b) Continue to lift the parcel in $5 \mathrm{a}$ to $400 \mathrm{MB}$ and subtract lifted parcel's temperature from $400 \mathrm{MB}$ temperature and record here . This is $700-400 \mathrm{MB}$ Filter Index Value.

c) Compare both the 700 - $500 \mathrm{MB}$ Filter Index and $700-400 \mathrm{MB}$ Filter Index, to the Monthly Filter Index.

If both Filter Index values fall in monthly range circle TSTMS. If one Filter Index falls outside the range circle CB VCNTY.

Step 6. Forecast

a) If the lifted layer $C=D$ was either conditionally stable or absolutely unstable and the Max Heating Index value required TSTMS to be circled forecast TSTMS TO OCCUR AT BKF unless the winds were from $360-150^{\circ}$ in Step 2. Then forecast CB VCNTY.

b) If the lifted layer was efther conditionally stable or absolutely unstable and Filter Index was used FCST TSTM TO OCCUR if TSTM was circled in Step 5; otherwise FCST CB VCNTY.

c) Circle final forecast TSTMS - NO TSTMS - CB VCNTY.

Step 7. 1971 Test Data

a) Using line drawn dry adlabatically from $600 \mathrm{MB}$ to surface and $1600 \mathrm{Z}$ BKF dew point determine initial point of lifted parcel's LFC and the termination point of LFC. Record here the vertical extent of LFC $\mathrm{ft}$.

Other Forecast Alds

1. Will trough (thermal, wind) pass BKF during forecast period?

2, Wi11 frontal Inversion affect MAX TEMP FCST?

3. W111 subsidence inversion CAP LFC BEFORE TSTM OCCUR?

MONTHLY INDEX RANGES (FOR DKF TSTMS FCST)

INDEX

Max Heating (1ess than)

$700-500 \mathrm{MB}$

Filter

$700-400 \mathrm{MB}$

Filter

$\begin{array}{cccl}\text { MAY } & \text { JUNE } & \text { JUL } & \text { AUG } \\ -1.5 & -2.5 & -3.5 & -2.5 \\ -1.0 \text { to }+3.5 & -1.0 \text { to }+3.0 & \text { less than }-2.0 & -1.0 \text { to }+3.5 \\ -1.0 \text { to }+3.5 & \text { less than }+2.5 & \text { less than }+2.5 & -2.0 \text { to }+4.0\end{array}$

FIG. 6. Henz I.ee Slope Thunderstorm Study Worksheet.

\section{c. Filter index}

When the Maximum Heating Index is near $( \pm 0.5 \mathrm{C})$ the critical value for the month, it is helpful to have a "filter" in order to separate thunderstorm days. To solve this problem, a purely empirical relationship was derived between modified Showalter Index values $(700-500 \mathrm{mb}$ and $700-400 \mathrm{mb}$ ) and thunderstorm occurrences. Filter Index values are derived by using $700-\mathrm{mb}$ DEN RAOB data and lifting a parcel from 700 to $500 \mathrm{mb}$ and then to $400 \mathrm{mb}$, and noting the temperature deviation of the lifted parcel from the sounding temperature at both 500 and 400 $\mathrm{mb}$. If both deviations fall within the ranges given at the bottom of the worksheet, thunderstorms are forecast. If only one deviation falls within the needed range, the forecast is for cumulonimbus in the vicinity.

\section{d. Mid-level steering winds}

The final parameter used in the study is the mid-level $(10,000-20,000 \mathrm{ft})$ steering wind. Since the thunderstorm source regions which affect BKF weather are related to higher topography, wind directions from $360-150^{\circ}$ are from non-source regions and constitute an automatic no thunderstorm forecast. This criterion was added when it became obvious that thunderstorms did not normally form in the regions to the north through southeast when the upper 
TABle 3. Year 1968-69 dependent data statistical analysis.

1. Contingency table summary

\begin{tabular}{lccc} 
& \multicolumn{2}{c}{ Forecast } & \\
& TSTM & TSTM & Total \\
\hline TSTM & 104 & 1 & 105 \\
No TSTM & 32 & 109 & 141 \\
Total & 136 & 110 & 246
\end{tabular}

2. Post-agreement (percent of time each forecast event occurred for a particular category)

\begin{tabular}{lcc} 
& \multicolumn{2}{c}{$\begin{array}{c}\text { lorecast } \\
\text { Observed thunderstorms }\end{array}$} \\
\hline Yes & Yes & No \\
No & 76.5 & 1 \\
Total & 23.5 & 99 \\
& 100 & 100
\end{tabular}

3. Prefigurance (percent of time each observed event was currently forecast)

Forecast thunderstorms

\begin{tabular}{|c|c|c|c|c|}
\hline Observed thunderstorms & & Yes & No & Total \\
\hline Yes & & 99 & 1 & 100 \\
\hline No & & 12 & 78 & 100 \\
\hline $\begin{array}{l}\text { 4. Percent correct: } \\
\text { 5. Heidke skill score: }\end{array}$ & $\begin{array}{r}87 \% \\
+\quad 0.74\end{array}$ & & & \\
\hline
\end{tabular}

winds were from these directions, regardless of the MLS and MHI forecasts and instability.

\section{Verification procedures}

Verification of a thunderstorm was based on the observation of any one of the following criteria during the valid period of the forecast within a $12-\mathrm{mi}$ radius of $\mathrm{BKF}$ :

1) Thunder reported at the BKF ROS

2) Rainshowers from cumulonimbus overhead at BKF ROS

3) Thunder reported overhead at DEN ( $7 \mathrm{n} \mathrm{mi}$ from BKF).

A no thunderstorm day was based on the nonobservance of these criteria. It may be argued that cumulonimbus overhead with rain showers is a weak verification criterion. However, thunder is usually associated with rainshowers at BKF during the summer, and the odds are high that thunder would be heard somewhere within the 12 -mi radius, if not at the observing site. This criterion was used for verification in only 26 out of 249 cases.

\section{Technique evaluation}

It was the purpose of this study to propose an accurate, objective thunderstorm/no thunderstorm forecast technique valid within a $12-\mathrm{mi}$ radius of $\mathrm{BKF}$ from 1200 to 2200 MDT during the thunderstorm season, May through August. A statistical evaluation of the technique is given in Tables 3-5. The technique was developed using 1968 and 1969 (dependent) data and tested on 1966, 1967 and 1970 (independent) data.
Considering a total of 615 forecasts, the technique achieved the following (see also Table 5):

1) $87.4 \%$ of all forecasts were correct.

2) +0.74 was the Heidke skill score for all forecasts (compared to +0.26 for Schowalter).

3) $77 \%$ of all thunderstorm forecasts, 246 out of 320 , were correct.

TABLe 4. Years 1966, 1967, 1970 independent data statistical analysis

1. Contingency table summary

\begin{tabular}{lccc}
\multicolumn{4}{c}{ Forecast } \\
& No & \\
TSTM & TSTM & TSTM & Total \\
No TSTM & 142 & 2 & 144 \\
Total & 42 & 183 & 225 \\
& 184 & 185 & 369
\end{tabular}

2. Post-agreement (percent of time each forecast event occurred for a particular category)

\begin{tabular}{lrr} 
& \multicolumn{2}{c}{ Forecast thunderstorms } \\
Observed thunderstorms & Yes & No \\
\hline Yes & 77 & 1 \\
No & 23 & 99 \\
Total & 100 & 100
\end{tabular}

3. Prefigurance (percent of time each observed event was correctly forecast)

\begin{tabular}{lrrr} 
Observed thunderstorms & \multicolumn{3}{c}{ Forecast thunderstorms } \\
& Yes & No & Total \\
\hline Yes & 99 & $\mathbf{1}$ & 100 \\
No & 19 & 81 & 100
\end{tabular}

4. Percent correct: $88 \%$

5. Heidke skill score: +0.76

TABLE 5. Final 1966-70 data statistical analysis.

1. Contingency table summary

\begin{tabular}{lccc} 
& \multicolumn{2}{c}{ Forecast } & \\
& TSTM & TSTM & Total \\
\hline TSTM & 246 & 3 & 249 \\
No TSTM & 74 & 292 & 366 \\
Total & 320 & 295 & 615
\end{tabular}

2. Post-agreement (percent of time each forecast event occurred for a particular category)

\begin{tabular}{lrr} 
& \multicolumn{2}{c}{ Forecast thunderstorms } \\
Observed thunderstorms & Yes & No \\
\hline Yes & 77 & 1 \\
No & 23 & 99 \\
Total & 100 & 100
\end{tabular}

3. Prefigurance (percent of time each observed event was correctly forecast)

\begin{tabular}{lrrr} 
& \multicolumn{3}{c}{ Forecast thunderstorms } \\
Observed thunderstorms & Yes & No & Total \\
\hline Yes & 99 & 1 & 100 \\
No & 20 & 80 & 100 \\
4. Percent correct $: 87.4 \%$ & & & \\
5. Heidke skill score $:+0.74$ & & &
\end{tabular}




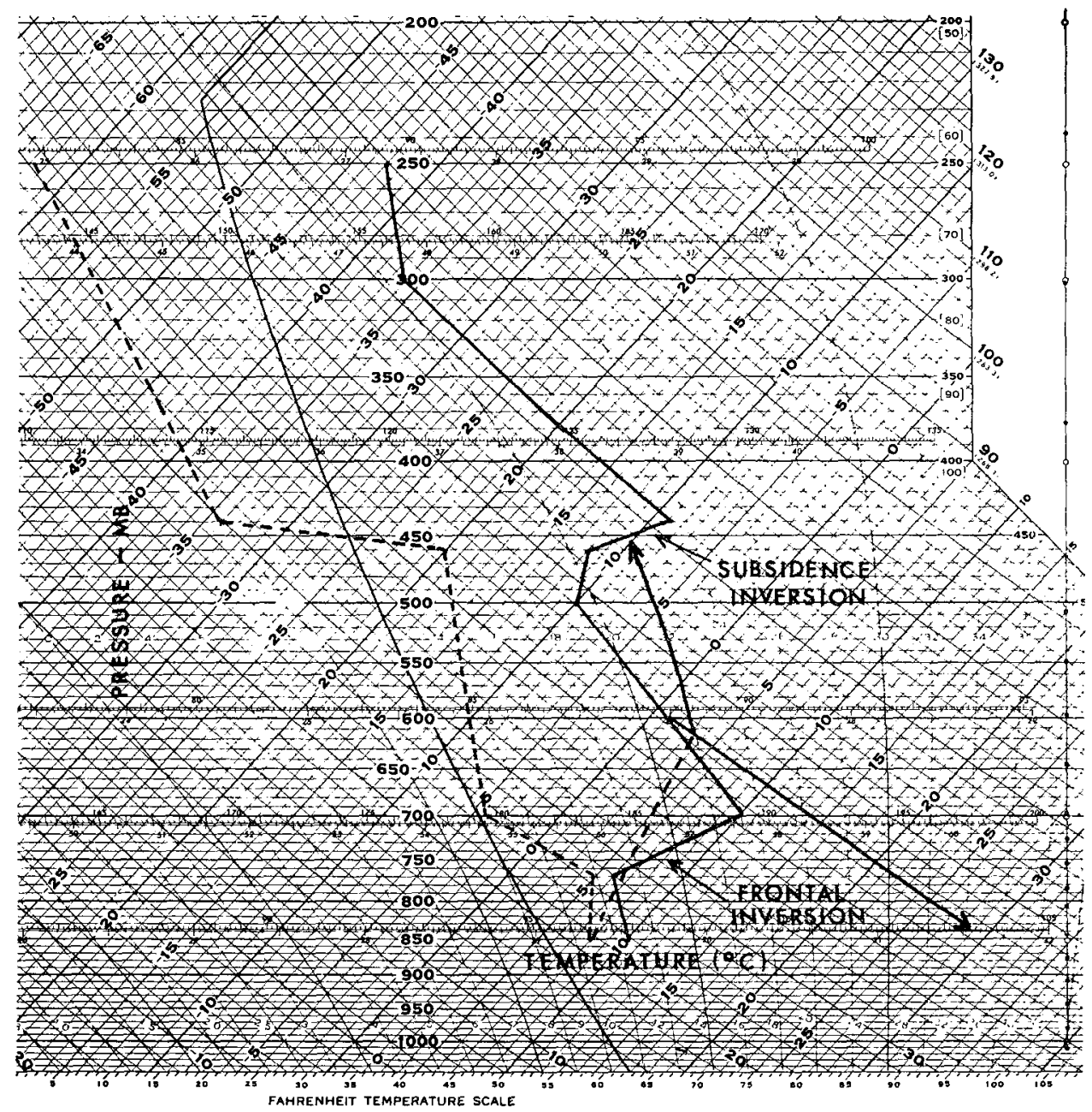

FIG. 7. Frontal and subsidence inversion examples.

4) $99 \%$ of all no thunderstorm forecasts, 292 out of 295 were correct.

The performance of the forecast technique suggests that the more important physical processes in lee slope thunderstorm formation have been accounted for. While the technique can be subjectively improved by the observant meteorologist, it represents, as it stands, an acceptable attempt to model certain hydrothermodynamic processes using the data available under real time deadlines. It can be applied at any lee slope mountain station with local modifications of the critical MHI values and of the layer to be lifted when calculating the MLS (elevation of the heated slopes varies from location to location). The direction of the source regions from the forecast station must also be considered.

\section{Synoptic modifications of the study}

Any objective study needs a certain degree of subjective modification if one is to adapt it to a given synoptic situation. In this section, several suggestions are made for improving the accuracy of the thunderstorm/no thunderstorm forecasts. None of these suggestions were used in making the objective forecasts verified.

\section{a. Cold frontal inversions}

The objective technique tends to over-forecast thunderstorms. Over half of the incorrect thunderstorm forecasts were related to days when strong coldfrontal inversions either persisted or formed during the forecast valid period. These inversions normally occur below $600 \mathrm{mb}$, which precludes dry adiabatic warming from the surface to $600 \mathrm{mb}$ which the MHI assumes. (Using the example shown in Fig. 7, the MHI assumes that the maximum temperature will reach $28.5 \mathrm{C}$ while in reality it should reach only $17 \mathrm{C}$.) The operational meteorologist can improve on the objective technique by estimating how much of the inversion will disappear as a result of diurnal heating and then forecasting a more reasonable maximum temperature. By using this 
new sounding approximation, he can improve the MHI value and obtain a better forecast.

\section{b. Northwesterly flow aloft: Synoptic-scale subsidence}

Another reason for over-forecasting thunderstorms may be the occurrence of northwesterly winds aloft. Northwesterly $700-300 \mathrm{mb}$ winds are generally associated with synoptic-scale subsidence. In addition, the height of the Front Range in a direction $270-300^{\circ}$ from BKF induces the strongest mechanical subsidence in the lee of the Rockies. Quite often a subsidence inversion forms between $450-350 \mathrm{mb}$, which caps the layer of free convection and stunts thunderstorm development (Fig. 7). In an effort to measure the importance of this suppression mechanism, the author estimated on 1971 data the depth of the layer of free convection of an MHI parcel. These estimates were correlated with thunderstorm occurrences. Initial results suggest that the depth of free convection must exceed $17,000 \mathrm{ft}$ before thunderstorms will develop but more research is needed on this concept.

When the upper winds are $320-350^{\circ}$ the thunderstorms which form northwest of BKF move over downtown Denver, between the Rockies and BKF, just outside the verification limits. Thus, even if thunderstorm development is correctly forecast, a miss is recorded on paper. Perhaps, new MHI ranges could be developed for northwesterly wind directions.

\section{c. 500-mb thermal troughs}

The final subjective modification pertains to those few cases when a thunderstorm occurs unforecast by the objective technique. It is normally related to passage of a $500-\mathrm{mb}$ thermal trough or increased low-level convergence ahead of a surface front. Though this study does not directly measure the destabilizing effects of low-level moisture injection, the jet stream, divergence aloft, thermal troughs, fronts, thickness ridges, or positive vorticity advection, it has missed forecasting only 3 of 249 thunderstorm days observed during the five years of the study. In all three cases strong cold air advection (5C cooling in $12 \mathrm{~h}$ ) associated with a $500-\mathrm{mb}$ thermal trough caused the incorrect forecast. The operational meteorologist should never forget to check for this destabilizing effect. The other mentioned parameters tend to influence thunderstorm. outbreak severity more than the mechanics of initial thunderstorm formation.

\section{Conclusion}

During the months of May through August the primary forecasting problem along the lee slopes of the Rocky Mountains is the occurrence of lee slope thunder- storms. At the time this study was started, no accurate method existed at BKF or DEN for forecasting thunderstorms during May through August. After observing daily growth characteristics of lee slope thunderstorms, a definite development pattern became evident which was modeled on the Skew $T, \log P$ diagram for use at detachment level. The forecast technique measures the stability of lifted thermal bubbles originating on the heated mountain slopes and combines this with a measure of the convective energy available at the time of maximum heating. The technique achieved a Heidke skill score of +0.74 over a five-year verification period. If suggestions for selectively modifying the objective technique are followed, forecast accuracy can be improved. Finally, the forecast technique should be applicable to any lee slope station or any plains station near a mountain range or plateau, provided that modifications are made for local topography and source regions.

Acknoweledgments. It is a pleasure to acknowledge the cooperation the author received from men stationed at Detachment 39, 25th Weather Service, Buckley ANG Base, Aurora, Colo., during the period 1968-71.

In particular, I would like to acknowledge the assistance of Captain Willie J. Dean, Jr., of Detachment 39, CWO-4 Carl Weiss (USAF, Ret.), and Major Robert Newhall, 25th Weather Squadron, for their continued assistance during the course of the study. This research was supported by the 5th Weather Wing Scientific Services Section of the Air Weather Service.

It is also my pleasure to acknowledge the capable manuscript assistance provided me by Dr. Thomas Schlatter of the National Center for Atmospheric Research. I thank Charles M. Umpenhour for the many stimulating discussions and background information provided during this study.

\section{REFERENCES}

Battan, Louis, and Richard Kosiodius, 1960: Design of a program of randomized seeding of orographic cumuli (unpubl. manuscript).

Braham, R. R., and M. Draginis, 1960: Roots of orographic cumuli. J. Meteor., 17, 214-226.

Dirks, R. A., 1968: A climatology of central Great Plains mesoscale convective systems. Tech. Rept. E-10-686, Dept. of Atmospheric Sciences, Colorado State University, $60 \mathrm{pp}$.

_, 1969: A theoretical investigation of convective patterns in the lee of the Colorado Rockies. Atmospheric Science Paper No. 145, Colorado State University, $112 \mathrm{pp}$.

Orville, H. D., 1965: A numerical study of the initiation of cumulus cloud over mountainous terrain. J. Almos. Sci., 22, 684-699.

-_, 1968: Ambient wind effects on the initiation and development of cumulus clouds over mountains. J. Atmos. Sci., 25, 385-403.

Samson, C. A., 1965: A comparison of mountain slope and radiosonde observations. Mon. Wea. Rev., 93, 327-330. 